THYROID

\title{
Scar satisfaction assessment after conventional thyroidectomy: follow-up results
}

\author{
II livello di soddisfazione riguardante la cicatrice dopo intervento di tiroidectomia: \\ risultati a distanza
}

\author{
Puthen Veetil Pradeep \\ Department of Endocrine Surgery, Baby Memorial Hospital, Kozhikode, Kerala, India 673004
}

\section{SUMMARY}

Objective. With the introduction of remote access thyroidectomy questions regarding patient satisfaction after trans-cervical thyroidectomy has been raised in several publications. As far as neck scars are concerned, patient satisfaction in the early post-operative period and long term are different. This study assessed patient satisfaction regarding their neck scar in the early post-operative period and at long term follow-up.

Methods. Retrospective study. Patients underwent total thyroidectomy by single surgeon. Scar satisfaction scores assessed at different time intervals $(<6$ weeks, 6 months, 2 years and 5 years after procedure). Scores of patients aged $<35$ years and $>35$ years were compared. Patient and observer scar assessment scales (PSAS, OSAS) and patient satisfaction score (PSS) were used.

Results. 595 patients were included (443 females and 152 males, age 19-77 years). Improvement was observed in the PSAS $(13.5 \pm 2.3$ at 6 weeks; to $4.32 \pm 1.37$ at 5 years; $\mathrm{p}<0.05)$ and OSAS $(7.32 \pm 1.35$ to $4.18 \pm 1.51 ; \mathrm{p}<0.05)$. PSS improved over time from $1.8 \pm 0.8$ to $0.92 \pm 0.66(\mathrm{p}<0.05)$. The satisfaction scores were higher in patients $<35$ years $(\mathrm{p}=0.003)$. The scores indicated excellent patient satisfaction and are similar to those published in the literature regarding minimally invasive surgery (MIS).

Conclusions. Proper incision placement and suturing resulted in excellent patient satisfaction regarding scars after conventional thyroidectomy.

KEY WORDS: thyroidectomy scar, patient satisfaction, scar assessment scale

\section{RIASSUNTO}

Obiettivo. Con l'introduzione delle interviste telematiche da accesso remoto, sono emerse diverse perplessità circa il grado di soddisfazione dei pazienti sottoposti a tiroidectomia. Per quanto riguarda le cicatrici sul collo, vi sono diversi livelli di soddisfazione del paziente nel primo periodo post operatorio rispetto al lungo periodo. Questo studio si propone di valutare la soddisfazione del paziente in relazione alla cicatrice sul collo nel primo periodo post-operatorio e nel follow-up a lungo termine.

Metodi. Studio retrospettivo. 595 pazienti sono stati sottoposti a tiroidectomia totale da parte dello stesso chirurgo. Sono stati assegnati diversi punteggi di soddisfazione della cicatrice, valutati a diversi intervalli di tempo (<6 settimane, a 6 mesi, 2 anni e 5 anni dopo la procedura). Sono stati confrontati i punteggi dei pazienti di età $<35$ anni e $>35$ anni. Sono state utilizzate le scale di valutazione della cicatrice del paziente e dell'osservatore (PSAS, OSAS) e il punteggio di soddisfazione del paziente (PSS).

Risultati. 595 pazienti sono stati inclusi nel presente studio (443 femmine e 152 maschi, età 19-77 anni). Il miglioramento è stato osservato nel PSAS (13,5 $\pm 2,3$ a 6 settimane; a $4,32 \pm 1,37$ a 5 anni; $p<0,05)$ e OSAS $(7,32 \pm 1,35$ a 4,18 $\pm 1,51 ; p<0,05)$. La PSS è migliorata nel tempo da $1,8 \pm 0,8$ a $0,92 \pm 0,66(p<0,05)$. I punteggi di soddisfazione erano più alti nei pazienti con età inferiore ai 35 anni $(p=0,003)$. I punteggi hanno indicato un'eccellente grado di soddisfazione del campione esaminato, i punteggi sono simili a quelli pubblicati in letteratura per quanto riguarda la chirurgia mininvasiva (MIS).

Conclusioni. L'adeguata pianificazione dell'incisione e adeguata sutura chirurgica produce un'eccellente grado di soddisfazione del paziente riguardo alle cicatrici dopo la tiroidectomia convenzionale.

PAROLE CHIAVE: cicatrice tiroidectomia, soddisfazione del paziente, scala di valutazione della cicatrice
Received: September 27, 2020 Accepted: November 17, 2020

\section{Correspondence}

Puthen Veetil Pradeep

Department of Endocrine Surgery, Baby Memorial Hospital, Kozhikode, Kerala, India 673004

Tel. +91 8281021234, +914952988234

E-mail: pradeepputhenveetil@yahoo.co.in

Funding

None.

\section{Conflict of interest}

The Authors declare no conflict of interest.

How to cite this article: Pradeep PV. Scar satisfaction assessment after conventional thyroidectomy: follow-up results. Acta Otorhinolaryngol Ital 2021;41:39-42. https://doi. org/10.14639/0392-100X-N1141

๑ Società Italiana di Otorinolaringoiatria e Chirurgia Cervico-Facciale

\section{(c) (1) $(9)$}

This is an open access article distributed in accordance with the CC-BY-NC-ND (Creative Commons Attribution-NonCommercial-NoDerivatives 4.0 International) license. The article can be used by giving appropriate credit and mentioning the license, but only for non-commercial purposes and only in the original version. For further information: https:// creativecommons.org/licenses/by-nc-nd/4.0/deed.en 


\section{Introduction}

Thyroid diseases are very common in India. Apart from hypothyroidism and hyperthyroidism, patients also present with goiters that can be benign or malignant. Malignant goiters and a significant proportion of benign goiters need thyroidectomy. Conventional neck surgery has stood the test of time and all surgeons are trained in this technique, even though outcomes differ based on individual experience ${ }^{1}$. One of the concerns raised with conventional thyroidectomy is related to the neck scar, especially after the alternative procedures like remote access and minimally invasive thyroidectomy (MIS) were introduced. As far as neck scars are concerned, patient satisfaction in the early post-operative period and long term are different. In this paper, the patient satisfaction regarding their scar in the neck in the early/late post-operative periods and at long term follow-up were assessed in Indian subjects.

\section{Methods}

We conducted a retrospective study in patients who underwent thyroid surgery at two tertiary care centres in South India. A total of 2594 patients underwent thyroidectomy during the period from 2008 to 2019. Patients who underwent neck dissection, central compartment dissection, hemi-thyroidectomy and foreign nationals were excluded. Patients who did not consent and those who did not present for follow-up were excluded. Patients with diabetes mellitus, obesity, smokers and those with keloid tendency $(n=9)$ were excluded. Cases of total thyroidectomy performed for benign or malignant goiters were included (Tab. I).

Patients were divided into groups based on duration of followup ( $<6$ weeks, 6 weeks to 6 months, 6 months to 2 years, 2 to 5 years and more than 5 years). It is well known that healing and scarring is different in younger and older individuals, especially in the long term. Hence, scoring was also assessed in patients who were $<35$ years and $>35$ years where the follow-up was $>1$ year. In these subgroups, the age and sex distribution did not show any significant differences.

The standard patient and observer scar assessment scale was used in this study (POSAS) ${ }^{2}$. This scale is shown in Table II. Observer scar assessment scale has five items and is scored $1-10$, where a value of 1 indicates normal skin and 10 the worst scar. The patient scar assessment scale considers six items with scores from 1 to 10 , with a score of 6 indicating normal skin and 60 the worst scar. Overall satisfaction was assessed with the patient satisfaction score (PSS). Very satisfied (1), satisfied (2), unsatisfied (3) and very unsatisfied (4) was the scoring system used for PSS. There are many different scar scales for assessing scar satisfaction, but the POSAS scale was used in this study ${ }^{3}$.

All surgeries were performed by a single endocrine surgeon.
Table I. Number of patients with duration of follow up.

\begin{tabular}{lcc} 
Follow-up duration & $\mathbf{N}=\mathbf{5 9 5}$ & Mean age (years) \\
$<6$ weeks & 16 & $43 \pm 11.2$ \\
6 weeks to 6 months & 101 & $52 \pm 9.8$ \\
6 months-1 year & 93 & $51 \pm 12.3$ \\
1-2 years & 105 & $49 \pm 11.6$ \\
2- 5 years & 132 & $54 \pm 13.6$ \\
$>5$ years & 148 & $56 \pm 14.8$ \\
\hline
\end{tabular}

The incision site is marked in one of the neck creases with the patient in the sitting position prior to the anaesthesia. Sub-platysmal flaps are raised. Straps are either cut/ divided depending on the size/difficulty in surgery. The rest of the procedure is as in standard thyroid surgery, preserving the recurrent and external laryngeal nerves and the parathyroids. Since the operating team of assistants and nurses were the same, the traction on the skin edges was kept to the minimum. Closures of the wound in all cases included subcutaneous absorbable vicryl (3,'O') followed by sub-cuticular suturing with 4 'O' vicryl. A drain was kept in place on a case to case basis.

Statistical analysis was performed using the SPSS (version 16.0, SPSS, Inc., Chicago, IL). Continuous values were reported as mean \pm standard deviation (SD). Differences in continuous variables were assessed by the student $t$-test. A $\mathrm{p}$ value of $<0.05$ was considered statistically significant. Repeated measures ANOVA was applied to compare scar satisfaction scores during follow-up.

\section{Results}

The number of patients available for follow-up after applying the exclusion/inclusion criteria is shown in Table $\mathrm{I}(\mathrm{n}=595)$. These were further divided into subgroups depending on the duration of follow-up as shown in Table I. Table I also shows the age distribution. The age and sex distribution did not show any significant differences. There were 443 females and 152 males. All patients were between 19 years to 77 years. Patients who had more than 1 year follow-up were further subgrouped by age less than 35 years and more than 35 years. Among patients who had follow up of $>1$ year, 210 were less than 35 years and 175 were more than 35 years. The mean length of the neck incision was $5.1 \pm 1.8 \mathrm{~cm}$. Tables III and IV show the results of the scores in the various groups. Table III shows that the patient (PSAS) and observer (OSAS) scar assessment scale scores improved as the duration of followup increased. Among patients with one year of follow-up the PSAS and OSAS scores were comparable to the scores seen in the study by Ma et al. on minimally-invasive thyroidectomy patients (PSAS: $13.27 \pm 4.56$ and OSAS $11.48 \pm 3.6)^{4}$. Table IV shows that the PSAS showed better scores in patients who are more than 35 years old irrespective of the duration 
Table II. The patient and observer scar assessment scales.

\begin{tabular}{|c|c|c|c|c|c|c|c|c|c|c|}
\hline \multirow[t]{2}{*}{ Observer component } & \multicolumn{5}{|c|}{ Normal skin } & \multicolumn{5}{|c|}{ Worst scar imaginable } \\
\hline & 1 & 2 & 3 & 4 & 5 & 6 & 7 & 8 & 9 & 10 \\
\hline \multicolumn{11}{|l|}{ Vascularity } \\
\hline \multicolumn{11}{|l|}{ Pigmentation } \\
\hline \multicolumn{11}{|l|}{ Thickness } \\
\hline \multicolumn{11}{|l|}{ Relief } \\
\hline \multicolumn{11}{|l|}{ Pliability } \\
\hline \multirow[t]{2}{*}{ Patient component } & & & No & & & & & Yes & & \\
\hline & 1 & 2 & 3 & 4 & 5 & 6 & 7 & 8 & 9 & 10 \\
\hline \multicolumn{11}{|l|}{ Is the scar painful? } \\
\hline \multicolumn{11}{|l|}{ Is the scar itching? } \\
\hline \multicolumn{11}{|l|}{ Is the colour of the scar different? } \\
\hline \multicolumn{11}{|l|}{ Is the scar more stiff? } \\
\hline \multicolumn{11}{|l|}{ Is the thickness of the scar different? } \\
\hline Is the scar irregular? & & & & & & & & & & \\
\hline
\end{tabular}

Table III. Scar satisfaction scores with duration of follow up.

\begin{tabular}{|c|c|c|c|c|c|c|c|}
\hline Follow-up duration & $N=595$ & PSAS & $P$ & OSAS & $P$ & PSS & $P$ \\
\hline$<6$ weeks & 16 & $13.5 \pm 2.3$ & \multirow{6}{*}{$<0.05$} & $7.32 \pm 1.35$ & \multirow{6}{*}{$<0.05$} & $1.8 \pm 0.8$ & \multirow{6}{*}{$<0.05$} \\
\hline 6 weeks to 6 months & 101 & $15.7 \pm 2.1$ & & $7.72 \pm 2.24$ & & $2.2 \pm 1.1$ & \\
\hline 6 months -1 year & 93 & $11.36 \pm 1.96$ & & $10.12 \pm 2.32$ & & $2.1 \pm 0.94$ & \\
\hline $1-2$ years & 105 & $10.62 \pm 2.37$ & & $8.12 \pm 1.76$ & & $1.3 \pm 0.52$ & \\
\hline $2-5$ years & 132 & $6.32 \pm 1.97$ & & $6.1 \pm 1.86$ & & $1.2 \pm 0.36$ & \\
\hline$>5$ years & 148 & $4.32 \pm 1.37$ & & $4.18 \pm 1.51$ & & $0.92 \pm 0.66$ & \\
\hline
\end{tabular}

Table IV. Scores in patients aged $<35$ years and $>35$ years.

\begin{tabular}{|c|c|c|c|c|c|c|c|}
\hline Follow-up duration & & PSAS & $P$ & OSAS & & PSS & $P$ \\
\hline $1-2$ years & $<35$ yr $(\mathrm{n}=56)$ & $11.13 \pm 2.11$ & \multirow{2}{*}{0.003} & $8.88 \pm 1.96$ & \multirow{2}{*}{0.01} & $1.6 \pm 0.52$ & \multirow{2}{*}{0.0001} \\
\hline$N=105$ & $>35$ yr $(\mathrm{n}=49)$ & $10.11 \pm 1.21$ & & $7.91 \pm 1.82$ & & $1.1 \pm 0.62$ & \\
\hline $2-5$ years & $<35$ yr $(\mathrm{n}=79)$ & $6.88 \pm 1.32$ & \multirow{2}{*}{0.003} & $6.46 \pm 1.88$ & \multirow{2}{*}{0.09} & $1.4 \pm 0.45$ & \multirow{2}{*}{0.0001} \\
\hline$N=132$ & $>35$ yr $(\mathrm{n}=53)$ & $6.11 \pm 1.62$ & & $5.95 \pm 1.45$ & & $1.01 \pm 0.25$ & \\
\hline$>5$ years & $<35$ yr $(\mathrm{n}=75)$ & $4.66 \pm 1.42$ & \multirow{2}{*}{0.003} & $4.46 \pm 1.49$ & \multirow{2}{*}{0.05} & $0.98 \pm 0.56$ & \multirow{2}{*}{0.28} \\
\hline$N=148$ & $>35$ yr $(n=73)$ & $4.02 \pm 1.14$ & & $4.03 \pm 1.21$ & & $0.87 \pm 0.68$ & \\
\hline
\end{tabular}

of follow-up. The OSAS also showed better satisfaction in patients $>35$ years during long term follow-up. The digital images of scars shown in Figure 1 along with duration of follow-up.

\section{Discussion}

On tracing the history of thyroid surgery in our department, the initial years showed high morbidity and even mortality ${ }^{1}$. With progress in anaesthesiology, the mortality became nil. However, the morbidity of hypocalcaemia and voice change persisted ${ }^{1}$. As surgical techniques were refined and the experience of surgeons increased, this was reduced to less than $1 \%$. The closure of a neck incision was given least importance and resulted in unsightly scars in the neck due to poor placement of incisions and poor suturing techniques (e.g. use of interrupted skin sutures). At this point in time, two developments took place: a group of surgeons adopted an aesthetic way of skin closure which included proper placement of incision in neck creases, and applying minimum traction on skin edges and closure using sub-cuticular absorbable sutures as do plastic surgeons. Another group introduced the evolving endoscopic surgery into the thyroid area thereby taking the incision in the neck to the axilla. Both these methods gave relief to patients who were disturbed due to the scar in their neck. 


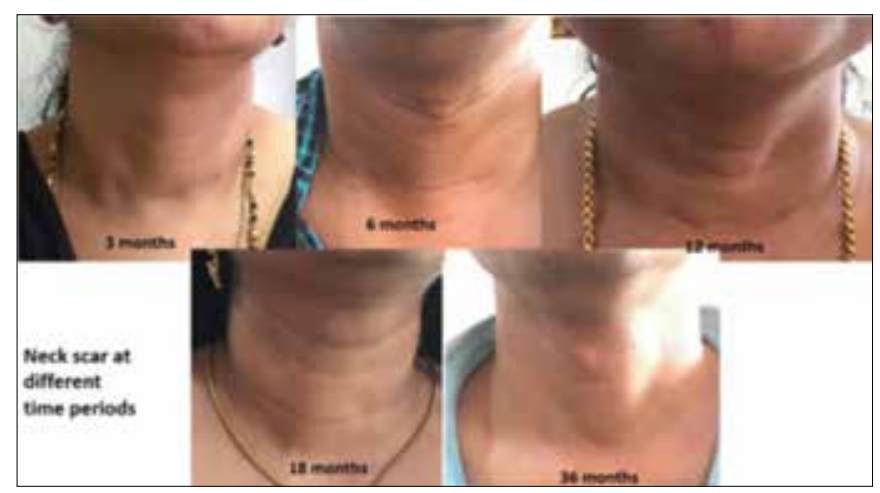

Figure 1. Neck scars at different times during follow-up.

Almost all Indian patients have creases in their neck, unlike the patients from Korea, Japan and Thailand. We have used these skin creases in our patient population who undergo thyroid surgery to mask the neck incision and resultant scar. However, whether this increases the patient satisfaction with their neck scars has not been addressed extensively in various ethnic populations. In this study, we investigated the patient's assessment of their scars and satisfaction using the POSAS and OSAS scale ${ }^{2}$. A number of scales are available for the assessment of scars ${ }^{3}$. POSAS focuses on scar severity from the clinician's and patient's point of view, although items represented in this scale may not adequately express the patient's perceptions and concerns ${ }^{3}$. Scales like the Vancouver scar scale, visual analogue scale and Stony Brook scar evaluation scales lack patient perception, while the latter two are photo-based without patient assessment of the scar ${ }^{3}$. Studies have shown that the POSAS is a reliable and complete scar evaluation tool ${ }^{2}$. With the POSAS, the consistency (internal) of the patient and observer scales appeared to be most acceptable (Cronbach's alpha 0.76 and 0.69 respectively $)^{2}$. It is well known that as time passes scars reduce in thickness and become cosmetically more acceptable. Hence, in our study we applied this scoring system to patients who had conventional neck surgery for thyroid after separating them into subgroups based on duration of follow-up. The scoring was separately applied to the different groups based on duration of follow-up (within 6 weeks, 6 weeks to 6 months and 6 months to 1 year). The scoring was also applied to patients who had long-term follow-up of $>1$ year. Since it has also seen that scar healing is better in older subjects, we examined long-term outcomes in patients less than 35 years and more than 35 years of age. A study by Ma et al. ${ }^{4}$, looked at scar scores in patients undergoing different types of surgery on the neck. They had excellent outcomes in patients undergoing aesthetic principles access thyroidectomy through the neck. Similarly, the study done by Lang et al. ${ }^{5}$ investigated scar outcomes in patients undergoing endoscopic surgeries through the axilla for the thyroid.
Studies have shown that scar maturation takes 6-18 months. Hence, the observation time is critical to judge outcomes of a surgical scar. Many factors influence patient satisfaction regarding their surgical scars. This includes the length, degree of hypertrophy, keloid formation, pigmentation and discomfort ${ }^{6}$. It has been shown that skin and soft tissue damage are produced by high retractor pressure and hence cosmesis is poor ${ }^{7}$. Thus, a small incision may not result is a good cosmetic result. Also, approaching a thyroidectomy through a small incision in the neck leads to a poor surgical field and increased risk of damage to structures like laryngeal nerves and parathyroid, apart from poor cosmesis due to excessive traction ${ }^{4}$. Our study has a large number of patients and we have used a validated scoring system to assess patient satisfaction regarding neck scars. All publications on endoscopic thyroidectomy highlight that a unsightly scar in the neck and patient dissatisfaction as reasons to adopt endoscopic remote access thyroidectomy. In this paper, we share our extensive experience in scar-related satisfaction (which is quite high) and also report that satisfaction improves as over long-term follow-up. Scar satisfaction improvement over longer periods of time has not been published to date.

\section{Conclusions}

Conventional thyroidectomy has stood the test of time in terms of safety and adoption of the technique. Scar satisfaction scores are excellent given the fact that the scar is in the anterior visible part of the neck. Scar satisfaction improves further with the longer duration of follow-up.

\section{References}

Dorairajan N, Pradeep PV. Vignette thyroid surgery: a glimpse into its history. Int Surg 2013;98:70-5. https://doi.org/ 10.9738/CC185.1

2 Draaijers LJ, Tempelman FRH, Yvonne A, et al. The patient and observer scar assessment scale: a reliable and feasible tool for scar evaluation. Plast Reconstr Surg 2004;113:1960-5. https://doi.org/ 10.1097/01.prs.0000122207.28773.5

3 Fearmonti R, Bond J, Erdmann D, et al. A review of scar scales and scar measuring devices. Eplasty 2010;10:354-63.

4 Xiao Ma, Qi-jun Xia, Guojun Li, et al. Aesthetic principles access thyroidectomy produces the best cosmetic outcomes as accessed using the patient and observer scar assessment scale. BMC Cancer 2017;17:654-62. https://doi. org/10.1186/s12885-017-3645-2

5 Lang BH, Wong KP. A comparison of surgical morbidity and scar appearance between Gasless, transaxillary endoscopic thyroidectomy and minimally invasive video assisted thyroidectomy. Ann Surg Oncol 2013;20:646-52. https:// doi.org/10.1245/s10434-012-2613-y

6 Toll EC, Loizou P, Davis CR, et al. Scars and satisfaction: do smaller scars improve patient reported outcome? Eur Arch Otorhinolaryngol 2012;269:30913. https://doi.org/10.1007/s00405-011-1613-z

7 Mow CS, Woolson ST, Ngarmukos SG, et al. .Comparison of scars from total hip replacements done in standard or a mini incision. Clin Orthop Relat Res 2005;441:80-5. https://doi.org/10.1097/01.blo.0000191317.85422.c3 